Supporting Information for:

\title{
Morphology of organic carbon coatings on biomass-burning particles and their role in reactive gas uptake
}

Leif G. Jahn, ${ }^{1, \wedge}$ Lydia G. Jahl, ${ }^{1}$ Bailey B. Bowers, ${ }^{1}$ and Ryan C. Sullivan ${ }^{1,2, *}$

'Department of Chemistry, Carnegie Mellon University, Pittsburgh PA 15213 USA

2Department of Mechanical Engineering, Carnegie Mellon University, Pittsburgh PA 15213

USA

${ }^{\wedge}$ Now at the Department of Chemical Engineering, University of Texas at Austin, Austin, TX 78705, USA

*Corresponding author: R. C. Sullivan, rsullivan@cmu.edu, 412-268-8462

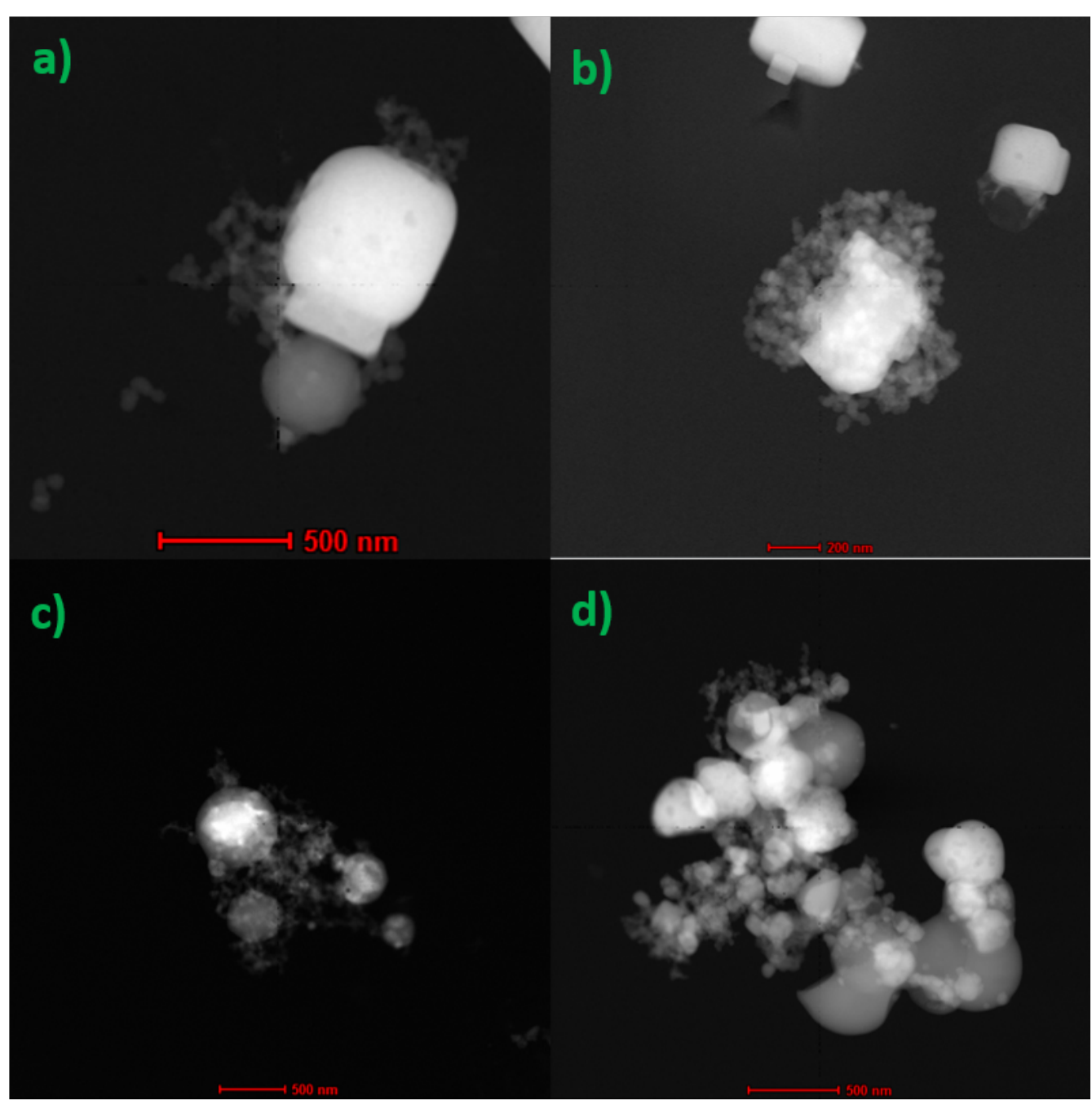

Figure S1. TEM images of tar ball and soot particles in BBA collected on substrates. The particles in a) and $b$ ) are from fresh swagrass BBA from the time-aging experiment. The particle in a) is an aggregate of a tar ball, soot, and $\mathrm{KCl}+\mathrm{NaCl}$ particles. The particle in $\mathrm{b}$ ) is a $\mathrm{KCl}$ salt particle encapsulated by a soot aggregate. The particle in c) is from aged ponderosa pine BBA and is several tar ball particles 
aggregated with soot. The particle in d) is from fresh cutgrass BBA and is an aggregate of organics, soot, and $\mathrm{KCl}$ particles.

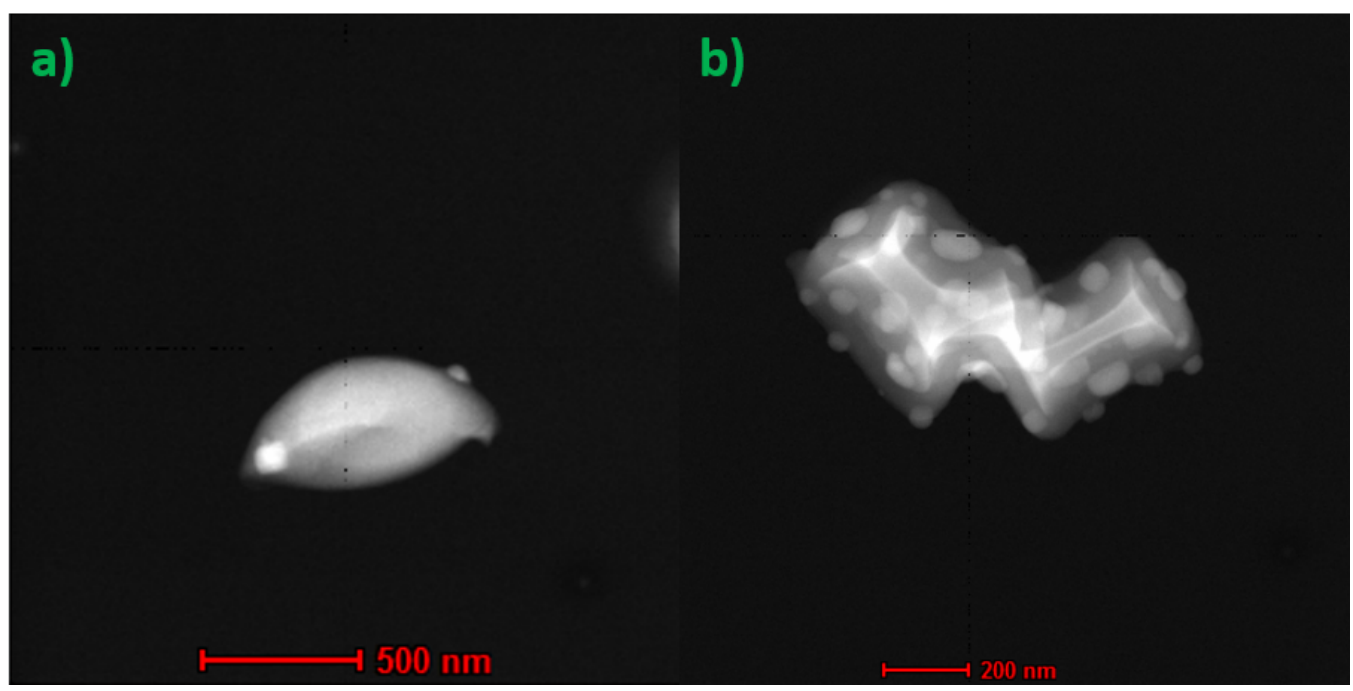

Figure S2. Examples of organic carbon-based particles that display morphologies different from those observed in most other particles. The particles in a) and b) are both from fresh sawgrass emissions and are both mostly organic carbon. The bright square in a) is $\mathrm{KCl}$, and the " $w$ " and ovoid features in b) contain some amount of $\mathrm{KCl}$.

Table S1. Summary of characteristics of fresh BBA from each fuel. The last two rows show the EDXmeasured O:C ratio averaged for all analyzed particles in the fresh and aged BBA samples. The entry “\% Na:K >0.30" denotes the number of particles with $>0.5 \% \mathrm{Na}$ and an Na:K atomic ratio $>0.30$.

\begin{tabular}{l|rrrrr}
\hline \multicolumn{1}{l}{ Sample } & Cutgrass & Sawgrass & \multicolumn{1}{c}{ Pon Pine } & \multicolumn{1}{c}{ Andropogon } & \multicolumn{1}{c}{ TA Sawgrass } \\
\hline \# particles & 1708 & 3498 & 741 & 837 & 1131 \\
\hline \% with K >0.1\% & 55.8 & 79.7 & 29.7 & 95.9 & 85.1 \\
\% with K >5.0\% & 34.1 & 38.8 & 4.6 & 70.6 & 60.9 \\
\% with K >10\% & 23.2 & 24.3 & 0.9 & 48.7 & 43.2 \\
\hline \% Na:K >0.30 & 7.2 & 14.7 & 2.7 & 3.6 & 26.6 \\
\hline Fresh O:C & 0.054 & 0.065 & 0.040 & 0.086 & 0.066 \\
Aged O:C & 0.104 & 0.088 & 0.052 & 0.125 & 0.064 \\
\hline
\end{tabular}




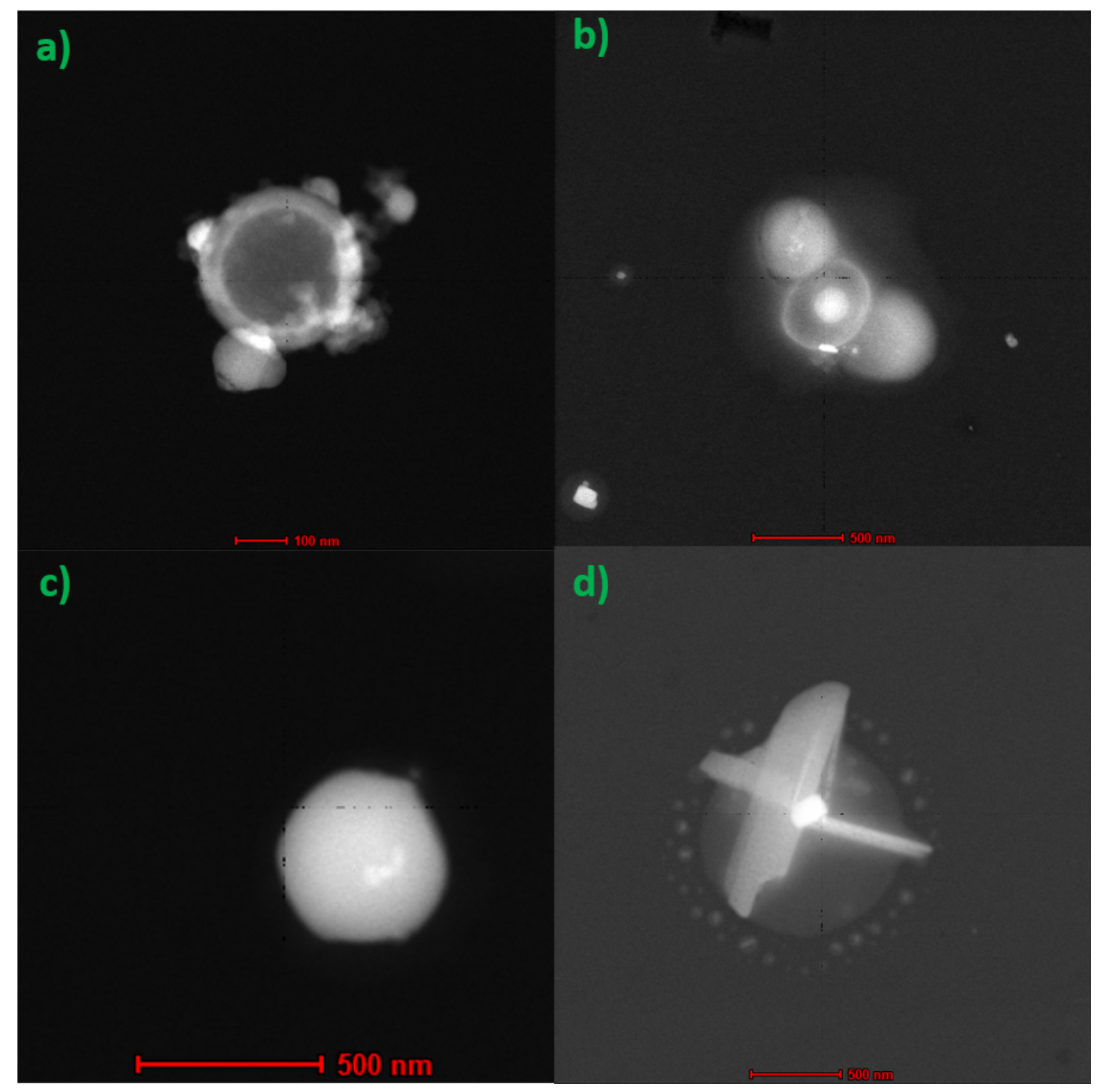

Figure S3. A larger view of the organic particles shown in Fig. 1. The particles are: a) Time-aged sawgrass BBA and shows an organic carbon shell around an organic core, with small amounts of soot and salt aggregates around the outer shell. b) Fresh sawgrass BBA and shows three spherical organic particles that are aggregated together with a small puddle of liquid-like organic material surrounding the particle (gamma contrast enhanced to show puddle). The center spheroid contains a small amount of $\mathrm{K}$ in the center core area and in the small bright spot at the lower edge of the particle. c) Fresh ponderosa pine BBA and is a spherical tar ball particle. D) Also fresh ponderosa pine BBA and shows a liquid-like organic puddle surrounding a mixture of organic material and $\mathrm{KCl}$. 


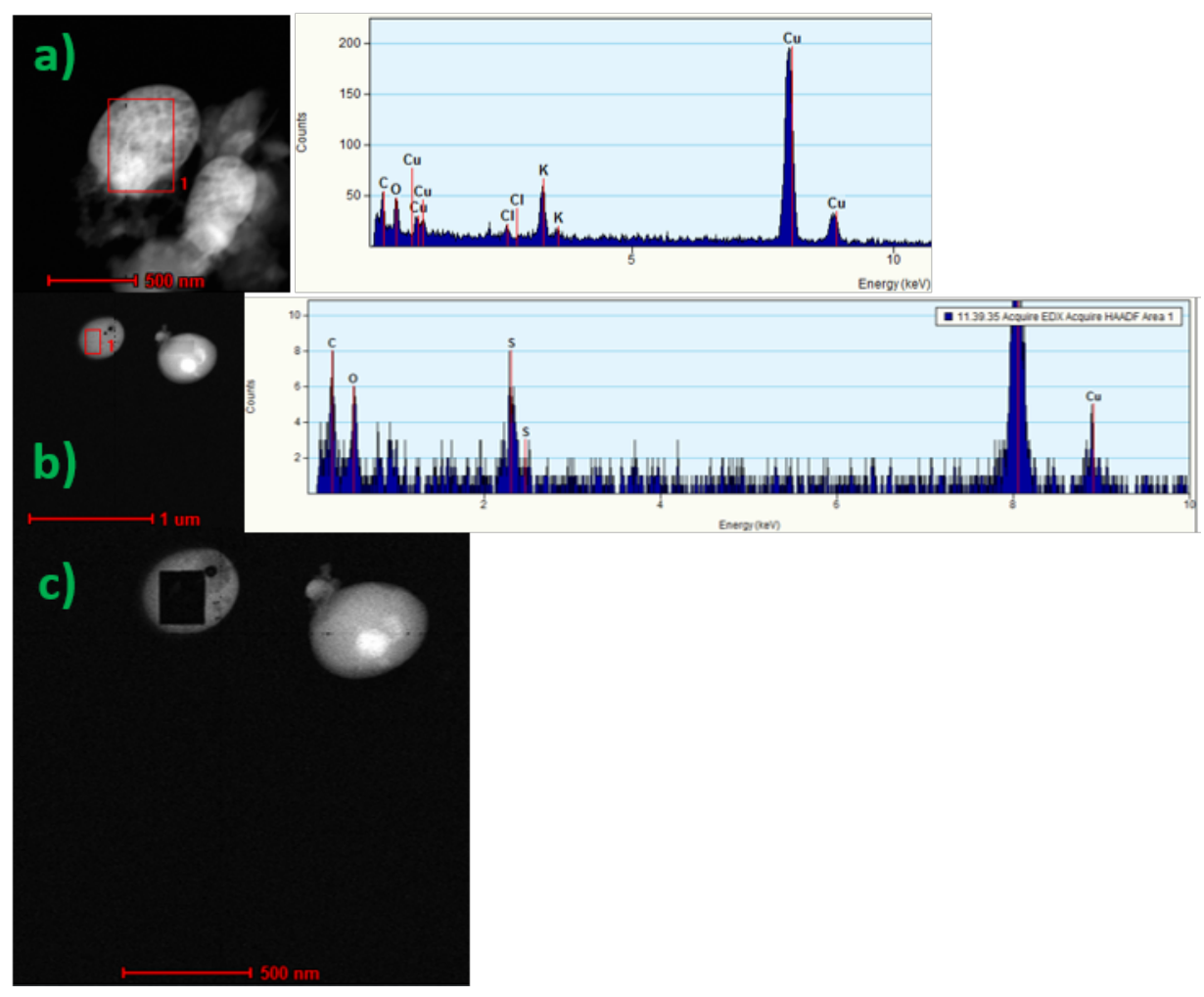

Figure S4. Examples of beam damage occurring to salt particles in aged sawgrass BBA. The particle in a) shows bubbling occurring throughout the particle as it begins to volatilize and disintegrate. The region of the particle in b) that was analyzed by EDX was completely vaporized (c) after a short exposure time. 


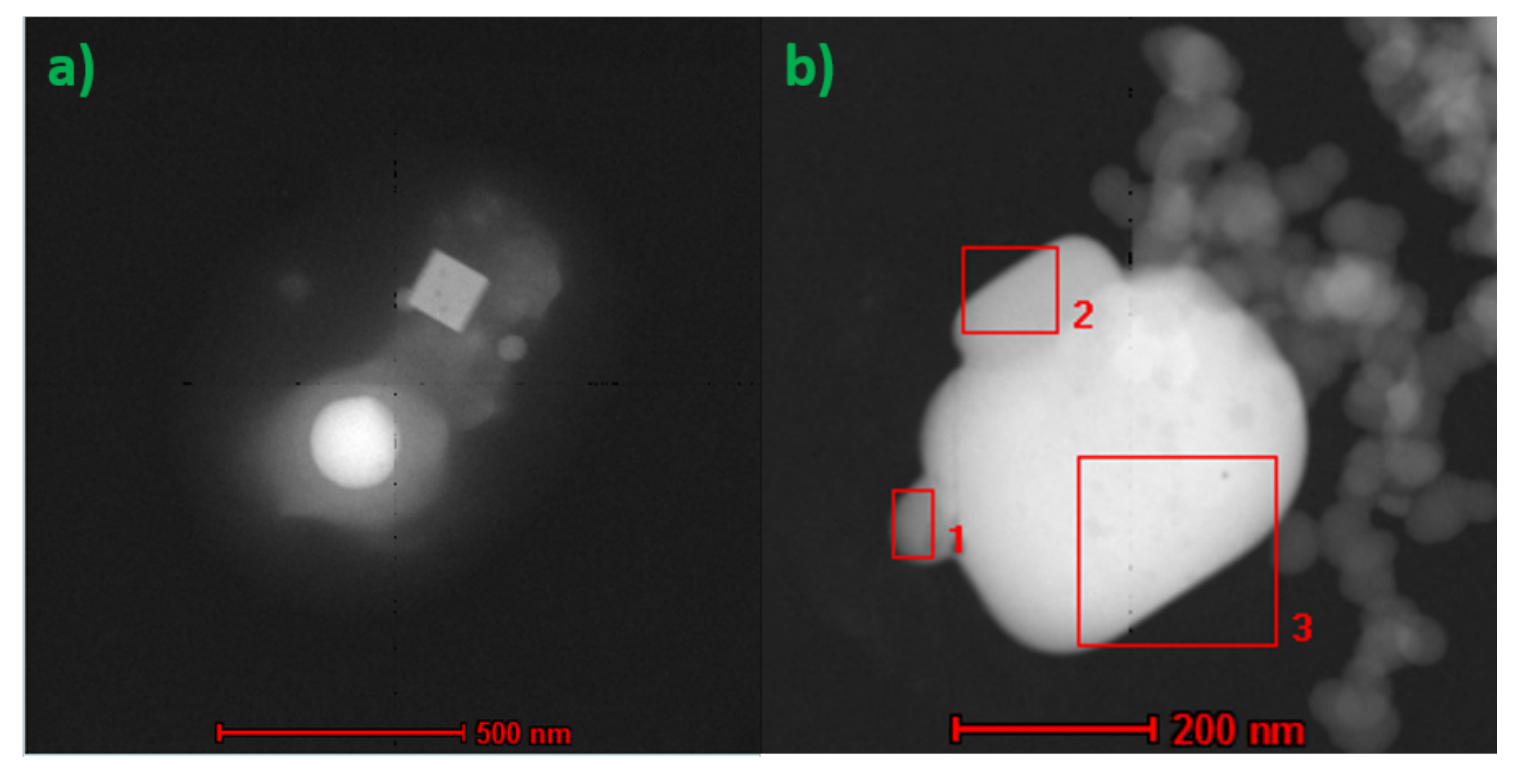

Figure S5. A larger view of the salt particles shown in Fig. 2. The particle in a) is from fresh sawgrass $\mathrm{BBA}$ and shows a cubic $\mathrm{KCl}$ region and a spherical $(\mathrm{Na}, \mathrm{K}) \mathrm{Cl}$ region within a matrix of organic material. The particle in b) is from fresh sawgrass BBA from the time-aging experiment and shows a salt particle aggregated with soot. Region (1) is composed of $\mathrm{K}_{2} \mathrm{SO}_{4}$, region (2) of $\mathrm{NaCl}$, and region (3) of $\mathrm{KCl}$.

Table S2. Bulk composition of wiregrass, black needle rush, saw palmetto, and longleaf pine needles measured through Inductively coupled plasma optical emission spectroscopy (ICP-OES) by Huffman Hazen Analytical Laboratories (Golden, CO, USA). Each quantity is reported as $\mu \mathrm{g}$ of element measured per $\mathrm{g}$ of fuel. The quantity $\mathrm{TX} * *$ is a total halide determination $(\mathrm{F}+\mathrm{Cl}+\mathrm{Br})$.

\begin{tabular}{r|rrrr}
\hline Fuel & Wiregrass & Black Needle Rush & Saw Palmetto & Longleaf Pine Needles \\
\hline TX** $(\mu \mathrm{g} / \mathrm{g})$ & 518 & 4760 & 4830 & 98 \\
Sodium $(\mu \mathrm{g} / \mathrm{g})$ & 149 & 2060 & 1810 & 45 \\
Magnesium $(\mu \mathrm{g} / \mathrm{g})$ & 438 & 1140 & 2930 & 987 \\
Potassium $(\mu \mathrm{g} / \mathrm{g})$ & 606 & 5030 & 1450 & 479 \\
Calcium $(\mu \mathrm{g} / \mathrm{g})$ & 1410 & 1840 & 5320 & 3430 \\
Aluminum $(\mu \mathrm{g} / \mathrm{g})$ & 36 & 37 & 13 & 365 \\
Silicon $(\mu \mathrm{g} / \mathrm{g})$ & 6120 & 7530 & 11800 & 5740 \\
Phosphorus $(\mu \mathrm{g} / \mathrm{g})$ & 229 & 501 & 613 & 275 \\
Sulfur $(\mu \mathrm{g} / \mathrm{g})$ & 304 & 2250 & 1240 & 276 \\
Iron $(\mu \mathrm{g} / \mathrm{g})$ & 18 & 62 & 20 & 34 \\
\hline
\end{tabular}




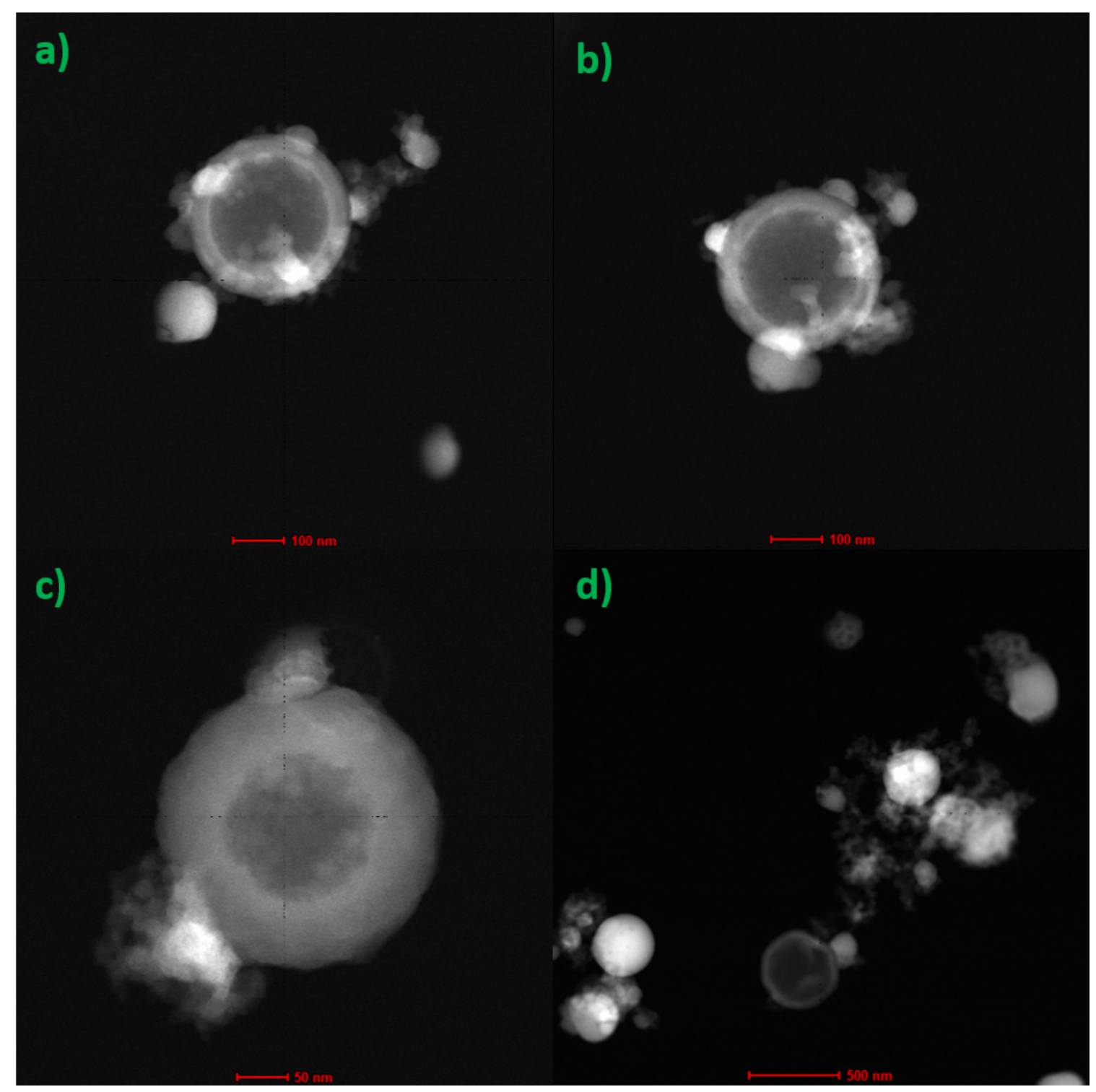

Figure S6. TEM images of particles from aged time-aged sawgrass BBA sample. The images in a) and b) show the same particle as in Fig. 1 a but imaged at an angle of $+45^{\circ}$ and $-10^{\circ}$ degrees, respectively, from the original image. The particles in c) and d) show a similar morphology but could not be analyzed across a significant degree of rotation due to proximity to the grid or other particles. 

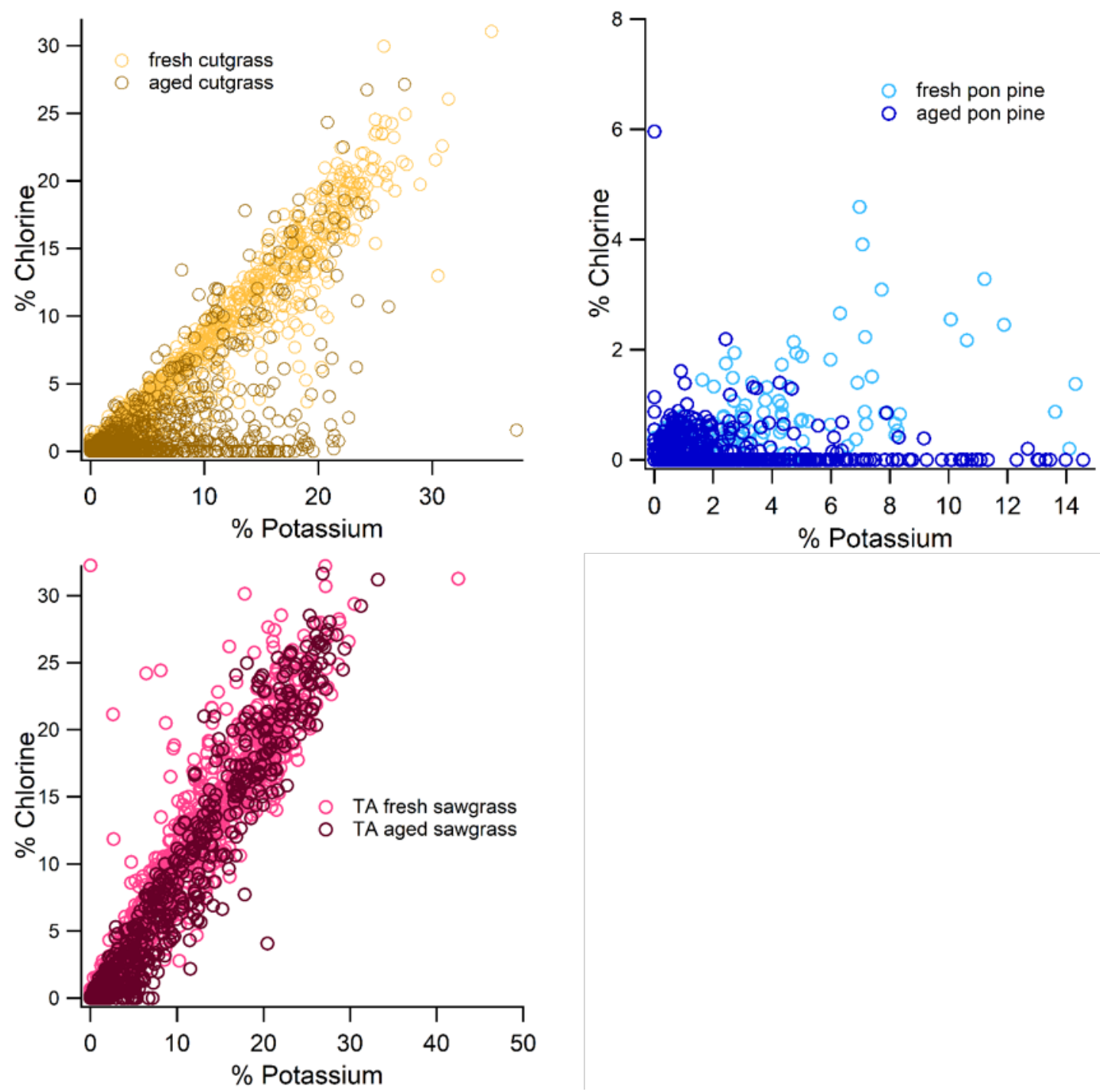

Figure S7. Plots of the $\mathrm{K}: \mathrm{Cl}$ ratio in fresh (light) and aged (dark) BBA from cutgrass (yellow), ponderosa pine (blue), and TA sawgrass fuels.

Table S3. Number of particles in aged BBA samples containing $>0.1 \% \mathrm{~K}$ that have undergone full, partial, or little chloride displacement during simulated atmospheric aging for each fuel.

\begin{tabular}{l|rrrrr}
\hline \multicolumn{1}{l}{ Sample } & Cutgrass & Sawgrass & Pon Pine & Andropogon & TA Sawgrass \\
\hline \# particles & 810 & 1169 & 701 & 788 & 646 \\
\hline \% little (Cl:K > 0.75) & 14.8 & 20.2 & 5.7 & 36.2 & 54.0 \\
\% partial (0.15 < Cl:K < 0.75) & 38.9 & 43.4 & 17.4 & 54.7 & 33.0 \\
\% full (Cl:K < 0.15) & 46.3 & 36.4 & 76.9 & 9.1 & 18.0 \\
\hline
\end{tabular}



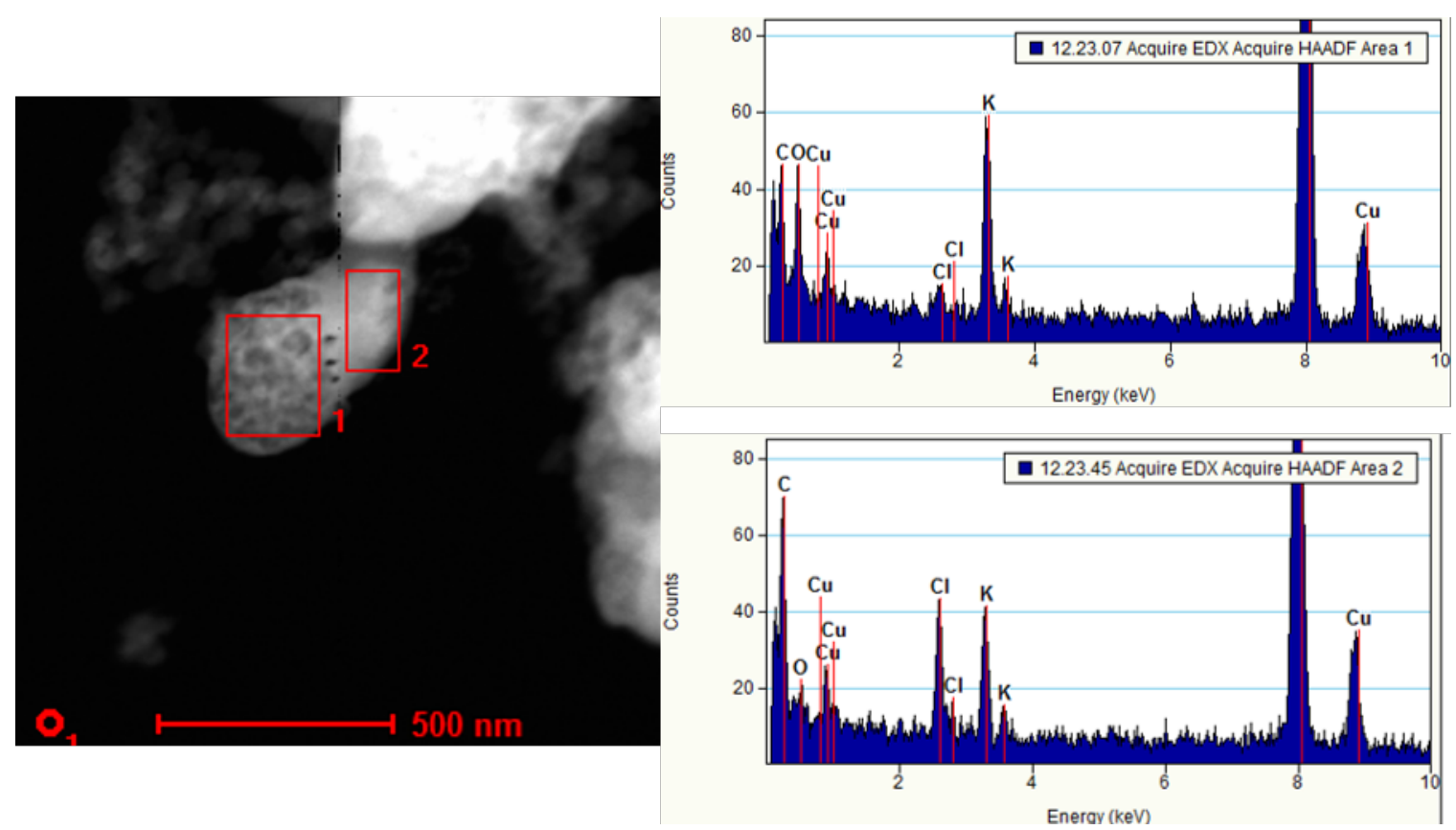

Figure S8. EDX spectra of the particle from aged sawgrass BBA shown in Fig. 7d. The particle appears to originally have been composed of $\mathrm{KCl}$ (region 2) but has undergone partial chloride displacement (region 1). The large peak centered near $8 \mathrm{keV}$ is due to Cu from the EM grid substrate. 


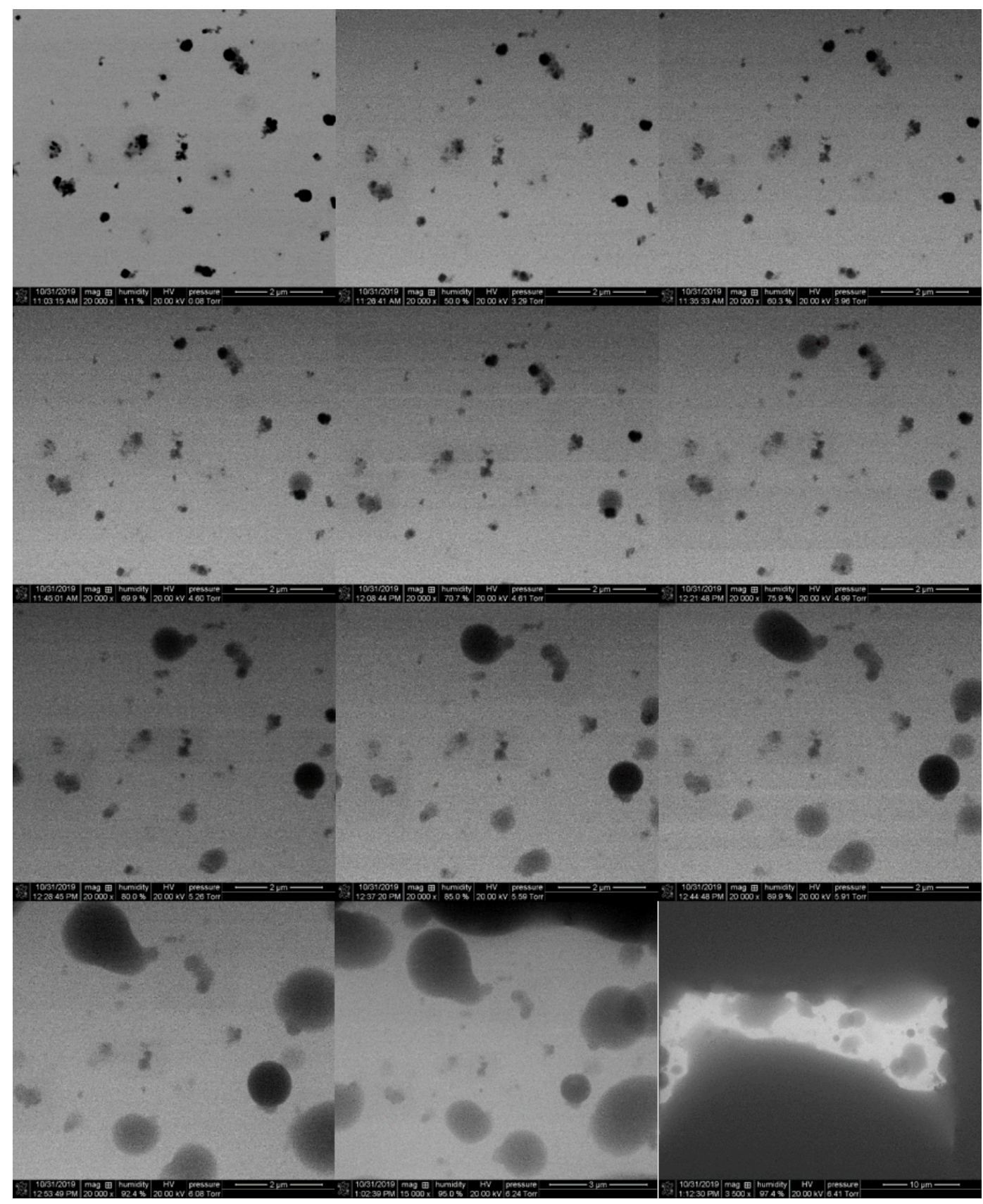

Figure S9. A complete stepwise view of the $\mathrm{RH}$ ramp from 1-97\% RH of the ESEM image shown in Fig. 5. BBA particles were collected from the combustion of black needle rush. The first response is visible at $70 \%$ where a small puddle begins to form around a single particle, and puddles begin to form around more particles at $76 \% \mathrm{RH}$. At $80 \% \mathrm{RH}$ puddles have formed around most particles that have any visible response during the $\mathrm{RH}$ ramp. At and above $85 \% \mathrm{RH}$, particles begin to grow more rapidly until they start to overlap and obscure the field of view at 95\% RH. 


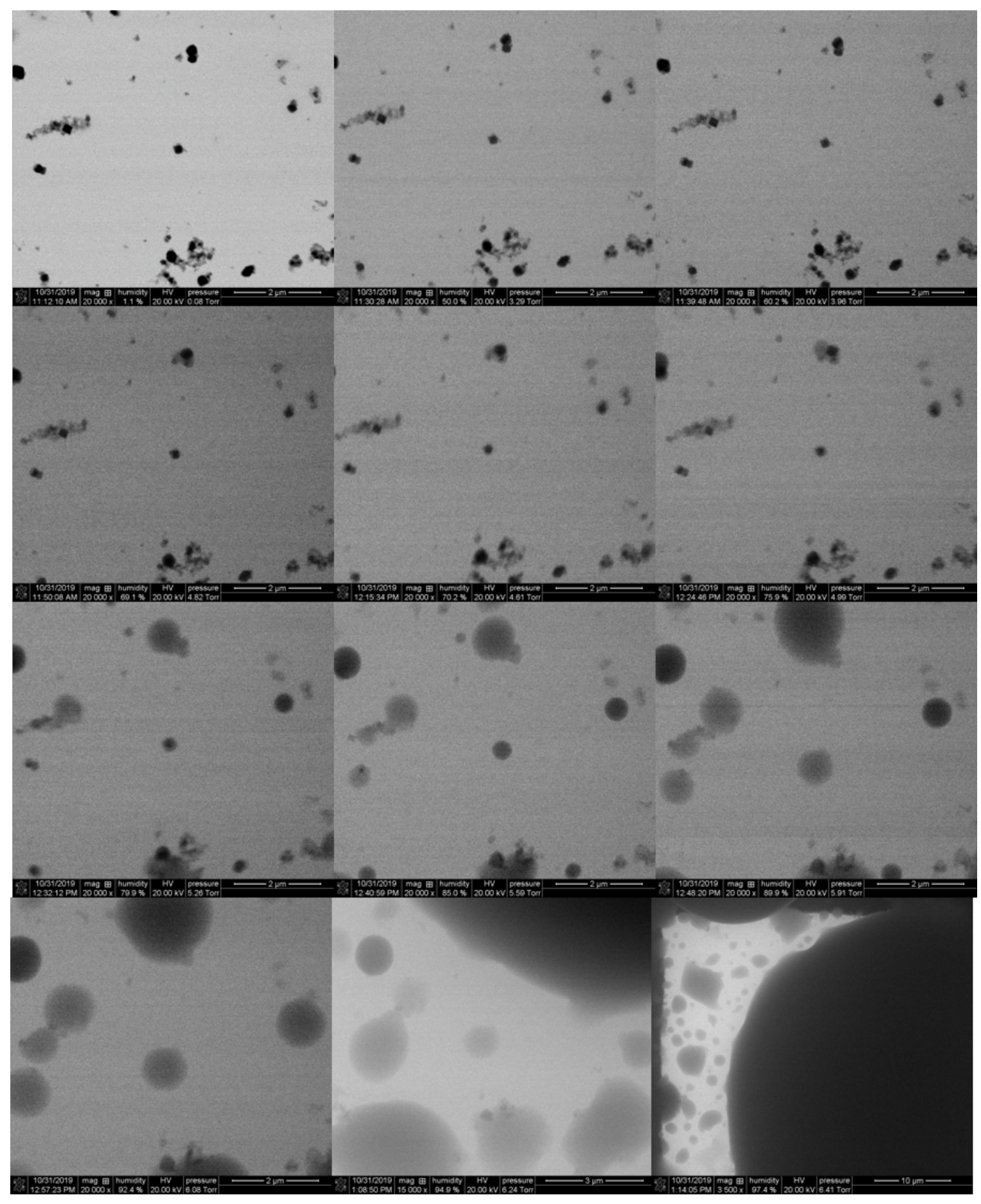

Figure S10. A complete stepwise ramp from 1-97\% RH from the sample shown in Figs. 5 and S9, here shown at another position on the TEM grid. BBA particles were collected from the combustion of black needlerush. Similar morphological responses are seen at comparable RH conditions between the two positions. 
Table S4. Summary of particles undergoing hygroscopic growth over the course of the RH ramp at each of the six beam positions analyzed. We take the period of initial hygroscopic growth to be the RH step where an approximate diameter increase of $>2$ is first observed (analysis performed using Image software ${ }^{1}$ ). Not all particles undergo clear hygroscopic growth over the course of the RH ramp and particles where growth may occur due to other factors besides direct gas-phase water uptake (such as growth of an overlapping neighboring particle) are not included.

\begin{tabular}{l|r|r|r|r|r} 
Spot \# & Particle \# & $60-70 \% \mathrm{RH}$ & $70-76 \% \mathrm{RH}$ & $76-80 \% \mathrm{RH}$ & $80-85 \% \mathrm{RH}$ \\
\hline 1 & 7 & 1 & 2 & 1 & 3 \\
2 & 12 & 1 & 3 & 5 & 3 \\
3 & 11 & 1 & 4 & 2 & 4 \\
4 & 10 & 1 & 4 & 3 & 2 \\
5 & 9 & 0 & 3 & 4 & 2 \\
6 & 3 & 0 & 1 & 1 & 1 \\
\hline Total & 52 & $8 \%$ & $33 \%$ & $31 \%$ & $28 \%$
\end{tabular}

\section{References}

1 C. A. Schneider, W. S. Rasband and K. W. Eliceiri, NIH Image to ImageJ: 25 years of image analysis, Nat. Methods, 2012, 9, 671-675. 